\title{
Identification of Sustainability Indicators and Evaluation of Transportation Corridors during Construction Using Fuzzy VIKOR Method
}

\author{
Shishir Bansal ${ }^{1}$, Sameer Verma ${ }^{2}$ and Santosh K. Singh ${ }^{1}$ \\ 1. Environmental Engineering Department, DTU (Delhi Technological University), Delhi 110092, India \\ 2. THDC (Tehri Hydro Development Corporation) Institute of Hydro Power Engineering and Technology, Uttarakhand 249001, \\ India
}

\begin{abstract}
Sustainability is popularly defined as meeting the needs of the present generation without compromising the ability of future generations to meet their own needs. Social, economic and environmental parameters are most commonly accepted as the three pillars of sustainability. In this paper, various sustainability indicators have been identified during the construction stage for elevated transportation corridors and thereafter classified under various categories. Using fuzzy VIKOR technique, sustainability evaluation of transportation corridors is made on two selected project sites of two different government organizations using various identified sustainability indicators, i.e., a 3.2-km long elevated road project under construction from Vikaspuri to Meerabagh in West Delhi by PWD (Public Works Department) and the metro rail elevated corridor (part) from Punjabi Bagh to Mayapuri as a part of Phase 3, Line 7 by DMRC (Delhi Metro Rail Corporation). The study is made at both sites in the midst of the construction period and it is identified that during the construction stage, the sustainability of these transportation corridors is just not limited to three pillars, but in actuality, it is much beyond that. From the study, it is inferred that the metro rail elevated corridor is a more sustainable corridor, in the context of the identified sustainability indicators.
\end{abstract}

Key words: Sustainability indicators, elevated corridors, metro corridor, governance, inner engineering, fuzzy VIKOR method.

\section{Introduction}

Identified as a global priority in early 1980s, the concept of sustainable development is most commonly defined as "the development that meets the needs of the present without compromising the ability of future generations to meet their own needs" [1]. While there is no standard definition of sustainable transportation, sustainability is largely captured in terms of transportation system effectiveness and system impact on economic productivity, environmental integrity and the social quality of life [2]. It was generally accepted that sustainable development and, more specifically, sustainable transport implied finding a proper balance between current and future environmental, social and

Corresponding author: Shishir Bansal, research scholar, research field: sustainability in transportation infrastructure. E-mail: bansal.shishir@gmail.com. economic qualities [3, 4]. However, detailed environmental, social and economic parameters required for a sustainable development were not identified till 2008.

In the year 2000, it was examined whether various future transport scenarios would be sustainable or not. First, environmental sustainable transport criteria, such as emissions of $\mathrm{CO}_{2}, \mathrm{NO}_{\mathrm{x}}$, VOC (volatile organic carbon), particles, noise and land use, were defined. Second, three environmental sustainable transport scenarios that would meet these criteria were defined. It was revealed that environmental sustainable transport goals can be met only if a large increase in technological development is assumed, and/or very stringent behavioral adaptations and changes in spatial and economic structures are assumed. However, the focus was on social indicators threatened by motorized 
transport, such as safety, health, perceived environmental qualities and community relationships [5].

Performance measures of sustainability, as reviewed by Jeon and Amekudzi [2], provided an extensive list of indicators sorted by the relative frequencies, with which they appeared in the 16 initiatives. All the reviewed transportation sustainability indicators may be classified into four major categories, i.e. transportation system effectiveness-related, economic, environmental and socio-cultural/equity-related indicators. It was inferred that the transportation-related and environmental indicators seem to be the most widely used indicators for sustainable transportation.

A research program for developing sustainable transportation indicators and data was conducted by sustainable transportation indicators subcommittee of the Transportation Research Board under the chairmanship of Litman [6]. He identified the sustainable transportation indicators that can be used for sustainable transportation evaluation. The principles for selecting sustainable transport indicators were variables which are selected and defined to measure progress toward an objective.

The study in this paper is started with characterizing of the emergent thinking about the rationale of transportation infrastructure sustainability in construction and the identification of the most appropriate indicators rather than following the popular indicators emerged in the most of the developed nations. Sustainability indicators of a transportation corridor during construction in an urban environment have been identified and detailed out. The studies have been conducted on a 3.2-km long elevated road project from Vikaspuri to Meerabagh in West Delhi by PWD (Public Works Department), Government of Delhi and a metro rail elevated corridor from Punjabi Bagh to Mayapuri as a part of Phase 3, Line 7 by DMRC (Delhi Metro Rail Corporation). During the midst of the construction period, it was identified that sustainability of these transportation corridors is just not limited to three pillars, but factually much beyond that. Actually, the traffic and transport policies differ greatly from city to city and from country to country, due to the people's travel patterns in those cities and countries. Mobility and accessibility, which are provided by the transport system, play a major role in shaping countries, influencing the location of social and economic activity, the form and size of cities and the style and pace of life by facilitating trade, permitting access to people and resources, and enabling greater economies of scale, worldwide and throughout history [7].

The study conducts on above two corridors and finally focuses on demonstrating a comparison between the two sites under construction by two government organizations, PWD and DMRC, under identical urban environment, using the fuzzy VIKOR technique for evaluating sustainability based on identified sustainability indicators with data furnished by conducting surveys (questionnaire pro forma) from the experts and public (residents/commuters).

This paper has been organized into two parts: (1) identification of sustainability indicators; (2) sustainability evaluation through the identified indicators for transportation corridors using fuzzy VIKOR method within a case study in New Delhi.

\section{Selection of the Two Corridors}

The traffic flow system of Delhi is a ring-radial pattern with two concentric roads popularly known as inner ring road and outer ring road, which are the lifelines of the city. These corridors were selected based on their location and the fact that they are under the similar urban environment. Moreover, these two sites were constructed by two different government organizations, PWD and DMRC. In this way, the working methodology of the two agencies can be compared on the basis of identified sustainability indicators under similar urban environment, e.g., the identical traffic flow, environmental and social conditions. The comparative study of these two 
corridors was possible because of the similar characteristics they possess and these characteristics are:

(1) Both the corridors are located in the western part of Delhi;

(2) Both the corridors are located on ring roads, i.e., inner and outer ring road;

(3) Both corridors are in the stretch of $3-\mathrm{km}$ to 5-km long;

(4) Both corridors are being constructed as elevated corridors with precast segments using overhead launchers on single pier, dual carriageways in thickly urban environment.

These sites were selected after visiting construction sites at various locations in Delhi and observing the common features between the two corridors.

\section{Methodology for the Identification of Sustainability Indicators}

The first step of the research work was the reconnaissance survey conducted sitting and observing in a car moving along with the other traffic passing through the selected corridor. The survey car was also stopped intermittently in order to better appreciate the various factors affecting the flow of traffic. This survey was conducted during different periods of the day for making observations under different traffic conditions. The traffic scenario was found almost uniform throughout the day except at night from 09:00 p.m. to 08:00 a.m. The survey also underlined that the major issues were linked to the flow of traffic, the execution and protection of ongoing works (e.g., security hazards, comfort level of commuters, residents, etc.). All such issues were identified and listed for a total of 39 elements.

The list of 39 identified issues was classified into six categories and each category is defined as sustainability indicators with these 39 criteria. At the end of the study, it is concluded that for an urban environment and developing city, like New Delhi, the triple pillar concept of sustainability does not get fit. It requires extension to suit the local conditions. Accordingly, the triple pillar concept is enlarged to six broad sustainability indicators, i.e., environmental, social, economics, technological, governance and inner engineering as classified in Table 1. Three new indicators play a vital role whenever the construction of infrastructure project is taken up in a thickly urban Environment, like Delhi.

It is essential that the technology for the construction adopted should be most suitable for that area so that caused inconvenience is reduced for the bare minimum period and also with least disrupting the surroundings. Governance plays an important role in the sense that the construction team gets full support, as well as the commuters, are well supported when subjected to inconvenience. Further, the commuters, as well as the project team members, must develop an inner strength to bear the mental fatigue while taking up the heavy construction activities and commuters able to bear the stress level and behave properly without losing the temper. The last indicator has been termed as inner engineering which otherwise may also be called theology or spirituality.

Based on the classification of these indicators, a questionnaire was framed and authors obtained opinions from experts in CRRI (Central Road Research Institute), PWD, BRO (Border Roads Organization), consultants, RITES (Railway India Technical and Economic Services), etc. Those opinions were organized in two scales for their quantitative analysis (Scale 1) and qualitative analysis (Scale 2). These scales are mentioned below.

Based on fuzzy theory, the rating was assigned to these 39 indicators, which is reflected in Table 4, Column 13 of this paper. Thereafter, a survey among commuters and residents nearby the project area was conducted in the form of questionnaire to appreciate the measures adopted by clients and the construction agency. The rating from 0 to 9 was assigned depending upon the inconvenience caused by the disruption. Best arrangements were to be assigned with higher marks 
Table 1 Identified sustainability indicators.

\begin{tabular}{|c|c|}
\hline Criteria & Sustainability indicators \\
\hline \multicolumn{2}{|c|}{ A. Environmental } \\
\hline $\mathrm{C} 1$ & Control on air pollution \\
\hline $\mathrm{C} 2$ & Control on drainage system due to construction activities \\
\hline $\mathrm{C} 3$ & Control on water logging during monsoon/rains \\
\hline $\mathrm{C} 4$ & Control on noise pollution due to construction activity during day \\
\hline $\mathrm{C} 5$ & Control on noise pollution during night \\
\hline $\mathrm{C} 6$ & Removal of trees/depletion of green belt \\
\hline $\mathrm{C} 7$ & Plantation scheme \\
\hline $\mathrm{C} 8$ & Any other technique used to make the project more green or eco-friendly \\
\hline \multicolumn{2}{|r|}{ 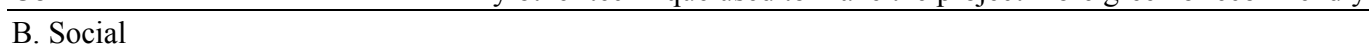 } \\
\hline C9 & Increase in the stress level of commuters \\
\hline $\mathrm{C} 10$ & Health of workers \\
\hline $\mathrm{C} 11$ & Welfare activities for family of workers \\
\hline $\mathrm{C} 12$ & Sanitation conditions \\
\hline $\mathrm{C} 13$ & First aid facility on site \\
\hline $\mathrm{C} 14$ & Safety measures \\
\hline $\mathrm{C} 15$ & Impact on health of residents \\
\hline $\mathrm{C} 16$ & Impact on safety of residents \\
\hline $\mathrm{C} 17$ & Public conveniences in the project area \\
\hline \multicolumn{2}{|c|}{ C. Economics } \\
\hline C18 & Increase in travel time \\
\hline $\mathrm{C} 19$ & Increase in travel cost \\
\hline $\mathrm{C} 20$ & Disturbance to the business/employment of nearby residents \\
\hline \multicolumn{2}{|c|}{ D. Technical } \\
\hline $\begin{array}{ll}\mathrm{C} 21 \\
\end{array}$ & Display of project details \\
\hline $\mathrm{C} 22$ & Display of mandatory, informatory and cautionary signage \\
\hline $\mathrm{C} 23$ & Traffic diversions \\
\hline $\mathrm{C} 24$ & Visibility and sight distance to moving traffic \\
\hline $\mathrm{C} 25$ & Lighting of construction site \\
\hline $\mathrm{C} 26$ & Barricading the site \\
\hline $\mathrm{C} 27$ & Aesthetics of project \\
\hline $\mathrm{C} 28$ & Handling of C\&D waste \\
\hline \multicolumn{2}{|c|}{ E. Governance } \\
\hline $\mathrm{C} 29$ & Ensuring the mobility of traffic in the project area \\
\hline $\mathrm{C} 30$ & Effective functioning of traffic marshals \\
\hline $\mathrm{C} 31$ & Unauthorized/improper parking in project area \\
\hline $\mathrm{C} 32$ & Maintenance of existing drainage system \\
\hline $\mathrm{C} 33$ & Maintenance of barricades \\
\hline $\mathrm{C} 34$ & Ensuring the SHE (safety, health and environment) at the site \\
\hline $\mathrm{C} 35$ & Maintenance of existing utilities \\
\hline $\mathrm{C} 36$ & Maintenance of existing greenery during construction \\
\hline \multicolumn{2}{|c|}{ F. Inner Engineering } \\
\hline C37 & Facilities of yoga/meditation \\
\hline $\mathrm{C} 38$ & Performance of rituals at site like Vishvakarma Puja, May Day \\
\hline $\mathrm{C} 39$ & Celebration during Festivals at site \\
\hline
\end{tabular}

Scale 1: Quantitative analysis on a scale 0 to 9 . The sustainability indicator with no importance may be assigned " 0 " value and most important indicator may be assigned "9" value. Accordingly, values may be assigned from 0 to 9 on the basis of its importance;

Scale 2: Qualitative analysis among VL (very low), L (low), M (medium), H (high) and VH (very high). The sustainability indicator with least importance may be assigned "VL" value and most important indicator may be assigned "VH" value. Values may be assigned accordingly from VL to $\mathrm{VH}$ on the basis of its importance. 
and least arrangements causing maximum inconvenience were assigned minimum marks. The survey outcome from the commuters and residents is reported in Table 5, Columns 2 and 3.

\section{Fuzzy Logic and Fuzzy VIKOR for Sustainability Evaluation}

\subsection{Preliminaries of Fuzzy Set Theory}

Some related definitions of fuzzy set theory adapted from Buckley [12], Dubois and Prade [13], Kaufmann and Gupta [14], Klir and Yuan [15], Pedrycz [16], Zadeh [17] and Zimmermann [18] are presented as follows.

\subsubsection{Definition 1}

A fuzzy set $\tilde{a}$ in a universe of discourse $X$ is characterized by a membership function $\mu_{\tilde{a}}(x)$ that maps each element $x$ in $X$ to a real number in the interval $[0,1]$. The function value $\mu_{\tilde{a}}(x)$ is termed the grade of membership of $x$ in $\tilde{a}$ [14]. The nearer the value of $\mu_{\tilde{a}}(x)$ is to unity, the higher the grade of membership of $x$ is in $\tilde{a}$.

\subsubsection{Definition 2}

A triangular fuzzy number (Fig. 1) is represented as a triplet $\tilde{a}=\left(a_{1}, a_{2}, a_{3}\right)$. Due to their conceptual and computation simplicity, triangular fuzzy numbers are very commonly used in practical applications $[15,16]$. The membership function of $\mu_{\tilde{a}}(x)$ triangular fuzzy number is given by:

$$
\mu_{\tilde{a}}(x)=\left\{\begin{array}{l}
0, x \leq a_{1} \\
\frac{x-a_{1}}{a_{2}-a_{1}}, a_{1}<x \leq a_{2} \\
\frac{a_{3}-x}{a_{3}-a_{2}}, a_{2}<x \leq a_{3} \\
0, x>a_{3}
\end{array}\right\}
$$

where, $a_{1}, a_{2}, a_{3}$ are real numbers and $a_{1}<a_{2}<a_{3}$. The value of $x$ at $a_{2}$ gives the maximal grade of $\mu_{\tilde{a}}(x)$, i.e., $\mu_{\tilde{a}}(x)=1$; It is the most probable value of the evaluation data. The value of $x$ at $a_{1}$ gives the minimal grade of $\mu_{\tilde{a}}(x)$, i.e., $\mu_{\tilde{a}}(x)=0$; It is the least probable value of the evaluation data. The narrower the interval $\left[a_{1}, a_{3}\right]$ is, the lower the fuzziness of the evaluation data is.

\subsection{Linguistic Variables and Fuzzy Set Theory}

In fuzzy set theory, conversion scales are applied to transform the qualitative terms into fuzzy numbers. A scale of $0 \sim 9$ is used to rate the criteria and the sites. Tables 2 and 3 present the conversion schemes for the qualitative, site and criteria ratings. Experts have used the five linguistic variables for weighting of criteria( as shown in Fig. 2) and also five linguistic variables for rating of sites which are shown in Fig. 3. The corresponding fuzzy numbers of linguistic variables for weights and site ratings are shown in Tables 2 and 3, respectively.

\subsection{Fuzzy VIKOR Technique for Evaluation}

The Serbian name VIKOR stands for "Vlse Kriterijumska Optimizacija I Kompromisno Resenje",

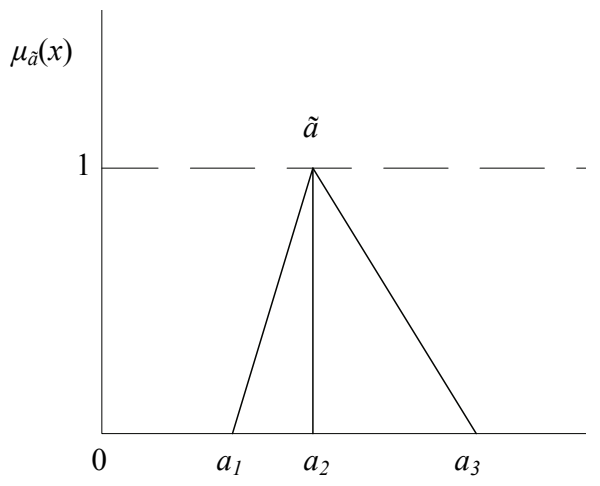

Fig. 1 Triangular fuzzy number $\tilde{a}$.

Table 2 Fuzzy transformation for qualitative criteria weightage.

\begin{tabular}{ll}
\hline Qualitative rating & Membership function \\
\hline VL (very low) & $(1,1,3)$ \\
L (low) & $(1,3,5)$ \\
M (medium) & $(3,5,7)$ \\
H (high) & $(5,7,9)$ \\
VH (very high) & $(7,9,9)$ \\
\hline
\end{tabular}

Table 3 Fuzzy transformation for qualitative site ratings.

\begin{tabular}{ll}
\hline Qualitative rating & Membership Function \\
\hline Very poor (VP) & $(1,1,3)$ \\
Poor (P) & $(1,3,5)$ \\
Fair (F) & $(3,5,7)$ \\
Good (G) & $(5,7,9)$ \\
Very good (VG) & $(7,9,9)$ \\
\hline
\end{tabular}




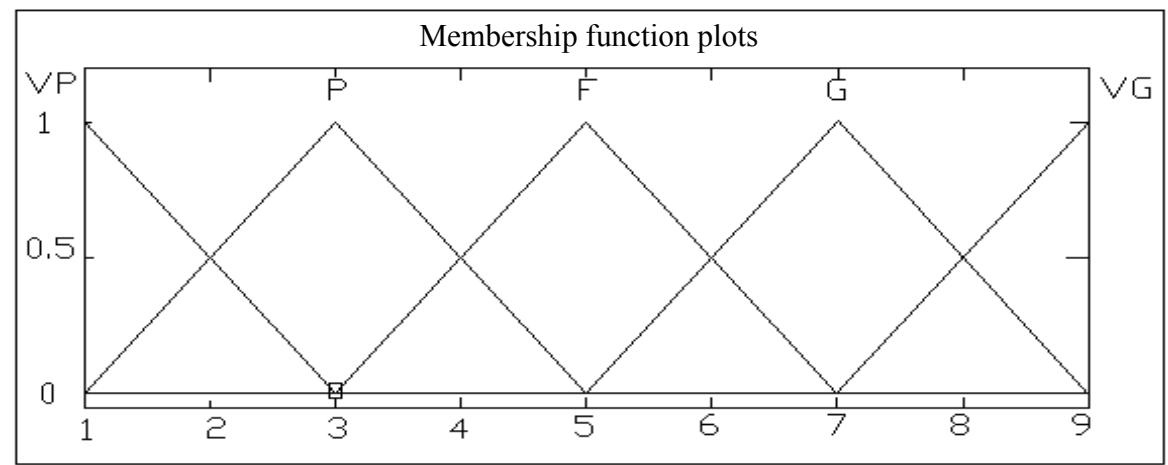

Input variable "qualitative/alternative"

Fig. 2 linguistic variables for weighting of criteria.

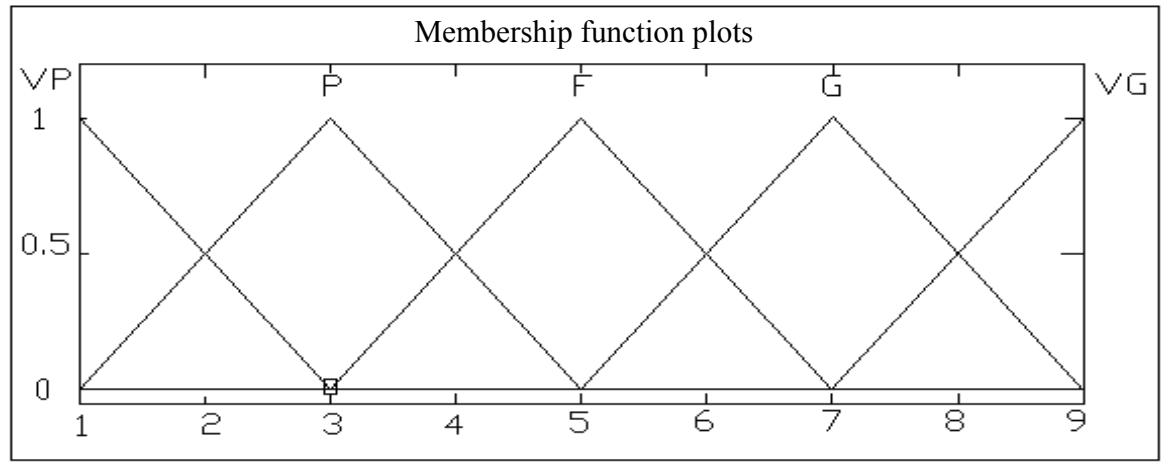

Input variable "qualitative/alternative"

Fig. 3 linguistic variables for rating of sites.

which means multi-criteria optimization and compromise solution developed by Opricovic in 1998 [8]. This method concentrates on ranking and selecting the best from a set of alternatives, which are associated with multi-conflicting criteria. Moreover, it makes it easy for the decision makers to reach the final decision by finding the compromise solution (closest to the ideal) of a problem. The basic principle of VIKOR is determining the positive-ideal solution, as well as the negative-ideal solution in the first place [9]. The positive-ideal solution is the best value of alternatives under the measurement criteria, and the negative-ideal solution is the worst value of alternatives under measurement criteria [10]. In the end, the precedence of the schemes can be arranged based on the closeness of the alternatives assessed value to the ideal scheme. Therefore, the VIKOR method is popularly known as a multi-criteria decision making method based on the ideal point technique [11].
4.3.1 Step 1: Assignment of Ratings to the Criteria and the Sites

Let us consider a set of $m$ sites called $A=\left(A_{1}, A_{2}, \ldots\right.$, $\left.A_{m}\right)$, which are to be evaluated against a set of $n$ criteria, $C=\left(C_{1}, C_{2}, \ldots, C_{n}\right)$. The criteria weights are denoted by $w_{j}(j=1,2, . ., n)$. The performance ratings of experts and public $D_{k}(k=1,2, \ldots, K)$ for each site $A_{i}(i=1,2, \ldots$, $m)$ with respect to criteria $C_{j}(j=1,2, \ldots, n)$ are denoted by:

$$
R_{k}=x_{i j k}=\left(a_{i j k}, b_{i j k}, c_{i j k}\right), i=1, \ldots, m ; j=1,2, \ldots, n ; k=1,
$$
$2, \ldots, K$ with membership function $\mu_{R_{k}}(x)$.

4.3.2 Step 2: Compute Aggregate Fuzzy Ratings for the Criteria and the Sites

If the fuzzy ratings of all experts is described as triangular fuzzy number $R_{k}=\left(a_{k}, b_{k}, c_{k}\right), k=1,2, \ldots, K$, the aggregated fuzzy rating is given by $R=(a, b, c), k=$ $1,2, \ldots, K$, and

$$
a=\min \left\{a_{k}\right\}, b=\frac{1}{k} \sum_{k=1}^{k} b_{k}, c=\max \left\{c_{k}\right\}
$$


If the fuzzy rating and importance weight of the $K$ th experts are $x_{i j k}=\left(a_{i j k}, b_{i j k}, c_{i j k}\right)$ and $w_{i j k}=\left(w_{j k 1}, w_{j k 2}, w_{j k 3}\right)$, $i=1,2, \ldots, m, j=1,2, \ldots, n$, respectively, the aggregated fuzzy ratings $\left(x_{i j}\right)$ of sites with respect to each criteria are given by $x_{i j}=\left(a_{i j}, b_{i j}, c_{i j}\right)$, and

$$
a_{i j}=\min \left\{a_{i j k}\right\}, b_{i j}=\frac{1}{k} \Sigma_{k=1}^{k} b_{i j k}, c_{i j}=\max \left\{c_{i j}\right\}
$$

The aggregated fuzzy weights $\left(w_{i j}\right)$ of each criterion are calculated as $w_{j}=\left(w_{j 1}, w_{j 2}, w_{j 3}\right)$, and

$$
\begin{gathered}
w_{j 1}=\min \left\{w_{j k 1}\right\} \\
w_{j 2}=\frac{1}{k} \sum_{k=1}^{k} w_{j k 1}, w_{j 3}=\max \left\{c_{j k 3}\right\}
\end{gathered}
$$

\subsubsection{Step 3: Compute the Fuzzy Decision Matrix}

The fuzzy decision matrix for the sites $(D)$ and the criteria $(W)$ is constructed as follows:

$$
\begin{aligned}
& \text { A1 A2 } \quad \ldots \text { Am }
\end{aligned}
$$

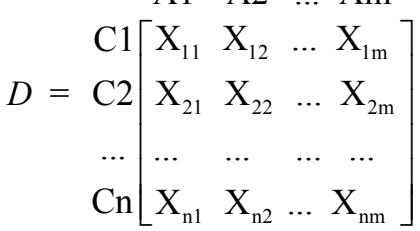

$$
\begin{aligned}
& i=1,2, \ldots, n ; j=1,2, \ldots, m \\
& W=\left(w_{1}, w_{2}, \ldots, w_{n}\right)
\end{aligned}
$$

4.3.4 Step 4: Defuzzify the Elements of Fuzzy Decision Matrix for the Criteria Weights and the Sites into Crisp Values

A fuzzy number $\tilde{a}=\left(a_{1}, a_{2}, a_{3}\right)$ can be transformed into a crisp number $a$ by employing the below equation:

$$
a=\frac{a_{1}+4 a_{2}+a_{3}}{6}
$$

4.3.5 Step 5: Determine the Best $f_{j}^{*}$ and the Worst Values $f_{j}^{-}$of All Criteria Ratings

The best $f_{j}^{*}$ and the worst values $f_{j}^{-}$of all criteria ratings can be determined when $j=1,2, \ldots, n$ :

$$
\begin{aligned}
& f_{j}^{*}=\max _{\mathrm{i}}\left\{x_{i j}\right\} \\
& f_{j}^{-}=\min _{\mathrm{i}}\left\{x_{i j}\right\}
\end{aligned}
$$

4.3.6 Step 6: Compute the Values of $S_{i}$ and $R_{i}$

The values of $S_{i}$ and $R_{i}$ can be computed using the following equations:

$$
\begin{gathered}
S_{i}=\sum_{j=1}^{n} w_{j} \frac{f_{j}^{*}-x_{i j}}{f_{j}^{*}-f_{j}^{-}} \\
R_{i}=\max x_{j} w_{j} \frac{f_{j}^{*}-x_{i j}}{f_{j}^{*}-f_{j}^{-}}
\end{gathered}
$$

4.3.7 Step 7: Compute the Value of $Q_{i}$

The value of $Q_{i}$ can be computed as follows:

$$
Q_{i}=v \frac{S_{i}-S^{*}}{S^{-}-S^{*}}+(1-v) \frac{R_{i}-R^{-}}{R^{-}-R^{*}}
$$

where:

$$
\begin{aligned}
& S^{*}=\min _{\mathrm{i}} S_{i} ; \\
& S^{-}=\max _{\mathrm{i}} S_{i} ; \\
& R^{*}=\min _{\mathrm{i}} R_{i} ; \\
& R^{-}=\max _{\mathrm{i}} R_{i} .
\end{aligned}
$$

And $v$ is the weight for the strategy of maximum group utility and $1-v$ is the weight of the individual regret.

4.3.8 Step 8: Rank the Alternatives

The alternatives can be ranked while sorting by the Values of $S, R$ and $Q$ in ascending order.

4.3.9 Step 9: Propose the alternative as a compromise solution

The alternative $\left(A^{(1)}\right)$ can be the best ranked by the measure $Q$ (minimum) if the following two conditions are satisfied.

(1) $\mathrm{C} 1$, acceptable advantage:

$$
Q\left(A^{(2)}\right)-Q\left(A^{(1)}\right) \geq D Q
$$

where, $A^{(2)}$ is the alternative with second position in the ranking list by $Q$ and

$$
D Q=1 /(J-1)
$$

(2) C2, acceptable stability in decision making:

The alternative $A^{(1)}$ must also be the best ranked by $S$ or/and $R$. The compromise solution is stable within a decision making process, which could be the strategy of maximum group utility (when $v>0.5$ is needed), or by consensus $v=0.5$, or with veto $(v<0.5)$. Please note that $v$ is the weight of the decision making strategy of maximum group utility.

If one of the conditions is not satisfied, then a set of compromise solutions are proposed, which consist of:

- Alternatives $A^{(1)}$ and $A^{(2)}$ if only the condition C2 is not satisfied;

- Alternatives $A^{(1)}, A^{(2)}, \ldots, A^{(M)}$ if the condition $\mathrm{C} 1$ is not satisfied; $A^{(M)}$ is determined by the relation $Q\left(A^{(M)}\right)-Q\left(A^{(1)}\right)<D Q$ for maximum $M$ (the position of these alternatives are in closeness) $[19,20]$. 


\section{Numerical Application}

This section presents the application of a chosen technique, namely "fuzzy VIKOR" for sustainability evaluation of two transportation project sites under construction (A1, A2) in the context of the city of Delhi. These projects are $3.2-\mathrm{km}$ long elevated road project under construction from Vikaspuri to Meerabagh in West Delhi by PWD (A1) and metro rail elevated corridor (part) from Punjabi Bagh to Mayapuri as a part of Phase 3, Line 7 by DMRC (A2).

A committee of 10 experts $(\mathrm{E} 1, \mathrm{E} 2, \ldots, \mathrm{E} 10)$ is formed to obtain qualitative ratings (Tables 2 and 3 ) for

Table 4 Qualitative assessments and aggregate fuzzy criteria ratings.

\begin{tabular}{|c|c|c|c|c|c|c|c|c|c|c|c|c|}
\hline \multirow{2}{*}{ Criteria } & \multicolumn{10}{|c|}{ Qualitative rating } & \multirow{2}{*}{ Aggregate fuzzy rating } & \multirow{2}{*}{ Crisp rating } \\
\hline & E1 & E2 & E3 & E4 & E5 & E6 & E7 & E8 & E9 & E10 & & \\
\hline $\mathrm{C} 1$ & VH & VH & VH & $\mathrm{H}$ & $\mathrm{H}$ & VH & VH & & VH & VH & $(5,8.55,9)$ & 8.03 \\
\hline $\mathrm{C} 2$ & $\mathrm{H}$ & VH & $\mathrm{M}$ & VH & M & M & $\mathrm{H}$ & VH & VH & $\mathrm{H}$ & $(3,8.2,9)$ & 7.47 \\
\hline $\mathrm{C} 3$ & VH & VH & M & VH & M & M & $\mathrm{H}$ & VH & VH & VH & $(3,7.6,9)$ & 7.07 \\
\hline $\mathrm{C} 4$ & $\mathrm{M}$ & $\mathrm{H}$ & $\mathrm{H}$ & $\mathrm{H}$ & $\mathrm{L}$ & $\mathrm{H}$ & M & $\mathrm{M}$ & $\mathrm{M}$ & $\mathrm{M}$ & $(1,5.6,9)$ & 5.40 \\
\hline $\mathrm{C} 5$ & $\mathrm{H}$ & VH & VH & VH & VH & $\mathrm{H}$ & $\mathrm{H}$ & $\mathrm{H}$ & $\mathrm{H}$ & VH & $(5,8,9)$ & 7.67 \\
\hline C6 & $\mathrm{VH}$ & VH & $\mathrm{M}$ & $\mathrm{H}$ & $\mathrm{H}$ & VH & VH & $\mathrm{H}$ & $\mathrm{H}$ & $\mathrm{H}$ & $(3,7.6,9)$ & 7.07 \\
\hline $\mathrm{C} 7$ & VH & VH & VH & $\mathrm{H}$ & $\mathrm{H}$ & $\mathrm{M}$ & $\mathrm{H}$ & M & $\mathrm{H}$ & $\mathrm{H}$ & $(3,7.2,9)$ & 6.80 \\
\hline $\mathrm{C} 8$ & & $\mathrm{H}$ & $\mathrm{M}$ & & $\mathrm{VH}$ & $\mathrm{H}$ & & & VH & $\mathrm{H}$ & $(3,7.33,9)$ & 6.89 \\
\hline C9 & $\mathrm{H}$ & VH & VL & VH & $\mathrm{M}$ & VH & VH & $\mathrm{H}$ & $\mathrm{M}$ & VH & $(1,7,9)$ & 6.33 \\
\hline $\mathrm{C} 10$ & VH & VH & $\mathrm{H}$ & VH & $\mathrm{H}$ & VH & $\mathrm{H}$ & $\mathrm{H}$ & $\mathrm{H}$ & VH & $(5,8,9)$ & 7.67 \\
\hline C11 & $\mathrm{VH}$ & $\mathrm{H}$ & $\mathrm{L}$ & VH & $\mathrm{H}$ & $\mathrm{H}$ & $\mathrm{H}$ & M & $\mathrm{H}$ & $\mathrm{H}$ & $(1,6.8,9)$ & 6.20 \\
\hline $\mathrm{C} 12$ & VH & VH & $\mathrm{H}$ & VH & $\mathrm{H}$ & VH & $\mathrm{H}$ & $\mathrm{H}$ & $\mathrm{H}$ & $\mathrm{H}$ & $(5,7.8,9)$ & 7.53 \\
\hline $\mathrm{C} 13$ & VH & VH & VH & VH & $\mathrm{H}$ & VH & VH & VH & $\mathrm{H}$ & VH & $(5,8.6,9)$ & 8.07 \\
\hline $\mathrm{C} 14$ & VH & $\mathrm{VH}$ & VH & VH & VH & VH & VH & VH & VH & VH & $(7,9,9)$ & 8.67 \\
\hline $\mathrm{C} 15$ & $\mathrm{VH}$ & VH & VH & VH & $\mathrm{M}$ & VH & VH & $\mathrm{H}$ & $\mathrm{H}$ & $\mathrm{H}$ & $(3,8,9)$ & 7.33 \\
\hline $\mathrm{C} 16$ & VH & VH & VH & VH & $\mathrm{H}$ & VH & VH & VH & VH & $\mathrm{H}$ & $(5,8.6,9)$ & 8.07 \\
\hline $\mathrm{C} 17$ & VH & VH & $\mathrm{M}$ & $\mathrm{H}$ & M & $\mathrm{H}$ & VH & VH & $\mathrm{H}$ & VH & $(3,7.6,9)$ & 7.07 \\
\hline $\mathrm{C} 18$ & $\mathrm{VH}$ & $\mathrm{VH}$ & $\mathrm{VH}$ & VH & M & VH & $\mathrm{H}$ & $\mathrm{H}$ & VH & $\mathrm{H}$ & $(3,8,9)$ & 7.33 \\
\hline $\mathrm{C} 19$ & $\mathrm{VH}$ & $\mathrm{VH}$ & VH & VH & M & M & $\mathrm{H}$ & $\mathrm{H}$ & VH & $\mathrm{H}$ & $(3,7.6,9)$ & 7.07 \\
\hline $\mathrm{C} 20$ & $\mathrm{H}$ & $\mathrm{H}$ & VH & VH & $\mathrm{L}$ & M & $\mathrm{H}$ & $\mathrm{H}$ & $\mathrm{H}$ & M & $(1,6.6,9)$ & 6.07 \\
\hline $\mathrm{C} 21$ & $\mathrm{H}$ & $\mathrm{H}$ & M & $\mathrm{H}$ & $\mathrm{L}$ & $\mathrm{L}$ & $\mathrm{H}$ & & VH & $\mathrm{L}$ & $(1,5.66,9)$ & 5.44 \\
\hline $\mathrm{C} 22$ & $\mathrm{VH}$ & VH & VH & VH & $\mathrm{VH}$ & VH & VH & $\mathrm{H}$ & VH & $\mathrm{H}$ & $(5,8.6,9)$ & 8.07 \\
\hline $\mathrm{C} 23$ & VH & VH & VH & VH & VH & VH & VH & VH & VH & $\mathrm{H}$ & $(7,8.8,9)$ & 8.20 \\
\hline $\mathrm{C} 24$ & $\mathrm{VH}$ & VH & $\mathrm{H}$ & VH & $\mathrm{M}$ & VH & VH & VH & $\mathrm{H}$ & $\mathrm{H}$ & $(3,8,9)$ & 7.33 \\
\hline $\mathrm{C} 25$ & $\mathrm{VH}$ & VH & $\mathrm{H}$ & VH & VH & VH & VH & VH & VH & $\mathrm{H}$ & $(5,8.60,9)$ & 8.07 \\
\hline $\mathrm{C} 26$ & $\mathrm{VH}$ & $\mathrm{VH}$ & $\mathrm{H}$ & VH & $\mathrm{H}$ & VH & VH & $\mathrm{H}$ & VH & VH & $(5,8.40,9)$ & 7.93 \\
\hline $\mathrm{C} 27$ & $\mathrm{M}$ & $\mathrm{H}$ & $\mathrm{L}$ & $\mathrm{H}$ & $\mathrm{H}$ & VH & M & M & $\mathrm{H}$ & $\mathrm{M}$ & $(3,6.00,9)$ & 6.00 \\
\hline $\mathrm{C} 28$ & $\mathrm{H}$ & $\mathrm{H}$ & M & VH & $\mathrm{H}$ & VH & VH & $\mathrm{H}$ & $\mathrm{H}$ & $\mathrm{H}$ & $(3,7.40,9)$ & 6.93 \\
\hline $\mathrm{C} 29$ & $\mathrm{VH}$ & VH & VH & VH & VL & VH & $\mathrm{H}$ & VH & VH & VH & $(5,8.00,9)$ & 7.67 \\
\hline $\mathrm{C} 30$ & VH & VH & $\mathrm{H}$ & VH & VH & VH & $\mathrm{H}$ & $\mathrm{H}$ & $\mathrm{H}$ & VH & $(5,8.20,9)$ & 7.80 \\
\hline C31 & $\mathrm{H}$ & $\mathrm{M}$ & M & VH & VL & VH & $\mathrm{H}$ & $\mathrm{H}$ & $\mathrm{H}$ & $\mathrm{M}$ & $(3,6.20,9)$ & 6.13 \\
\hline C32 & VH & VH & $\mathrm{H}$ & VH & $\mathrm{H}$ & VH & $\mathrm{H}$ & VH & VH & VH & $(5,8.40,9)$ & 7.93 \\
\hline $\mathrm{C} 33$ & $\mathrm{H}$ & $\mathrm{M}$ & $\mathrm{H}$ & VH & $\mathrm{H}$ & VH & $\mathrm{H}$ & VH & $\mathrm{H}$ & $\mathrm{M}$ & $(3,7.20,9)$ & 6.80 \\
\hline C34 & VH & $\mathrm{H}$ & VH & VH & $\mathrm{VH}$ & VH & VH & VH & $\mathrm{H}$ & $\mathrm{H}$ & $(5,8.40,9)$ & 7.93 \\
\hline $\mathrm{C} 35$ & VH & $\mathrm{H}$ & VH & VH & $\mathrm{VH}$ & VH & $\mathrm{H}$ & VH & $\mathrm{H}$ & $\mathrm{H}$ & $(5,8.20,9)$ & 7.80 \\
\hline $\mathrm{C} 36$ & VH & VH & $\mathrm{M}$ & VH & $\mathrm{H}$ & $\mathrm{H}$ & $\mathrm{H}$ & $\mathrm{H}$ & $\mathrm{H}$ & VH & $(5,7.60,9)$ & 7.40 \\
\hline C37 & M & $\mathrm{M}$ & M & $\mathrm{H}$ & VL & M & VL & $\mathrm{L}$ & VL & $\mathrm{L}$ & $(1,3.60,7)$ & 3.73 \\
\hline $\mathrm{C} 38$ & VL & $\mathrm{L}$ & $\mathrm{H}$ & VH & $\mathrm{VH}$ & M & VL & M & $\mathrm{H}$ & $\mathrm{L}$ & $(1,5.00,9)$ & 5.00 \\
\hline C39 & $\mathrm{M}$ & VL & $\mathrm{VH}$ & $\mathrm{H}$ & VL & M & VL & M & M & VL & $(1,4.00,9)$ & 4.33 \\
\hline
\end{tabular}


the criteria and the alternatives. These ratings are presented in Table 4.

The aggregated fuzzy weights $\left(w_{i j}\right)$ of criteria are obtained using Eq. (3). For example, for Criteria $\mathrm{C} 1$ (Qualitative Rating $=(\mathrm{VH}, \mathrm{VH}, \mathrm{VH}, \mathrm{H}, \mathrm{H}, \mathrm{VH}, \mathrm{VH}$, “-”, $\mathrm{VH}, \mathrm{VH})$ ), the aggregated fuzzy weight is given by $w_{j}=\left(w_{j 1}, w_{j 2}, w_{j 3}\right)$, and

$$
\begin{gathered}
w_{j 1}=\min (7,7,7,5,5,7,7,7,7) \\
w_{j 2}=1 / 9 \times(9+9+9+7+7+9+9+9+9) \\
w_{j 3}=\max (9,9,9,9,9,9,9,9,9) \\
w_{j}=(5,8.55,9)
\end{gathered}
$$

The aggregated fuzzy weights $w_{j}$ is transformed into crisp number $w_{c}$ using Eq. (7). For example, for Criteria $\mathrm{C} 1, w_{j}=(5,8.55,9)$, we have $w_{c}=$ $\frac{1 \times 5+(4 \times 8.55)+9}{6}=8.03$. Likewise, we compute the aggregate weights for the remaining criteria. The results for aggregate weights of the 39 criteria are presented in the last column of Table 4.

The qualitative ratings for the two sites, PWD (A1) and DMRC (A2), provided by the public (commuters/residents) are converted into fuzzy triangular numbers and then aggregate ratings are generated using the Eq. (2). Table 5 presents the aggregate fuzzy decision matrix for the two alternative sites.

After obtaining the fuzzy decision matrix and fuzzy/crisp criteria weights, the fuzzy VIKOR technique for sustainability evaluation is applied. The results are presented as follows.

First of all, generate aggregate crisps ratings for the two sites using Eq. (6). Based on these values, we will compute the best $f_{j}^{*}$ and the worst values $f_{j}^{-}$of the 39 criteria using Eqs. (8-9). Table 6 presents the results for the aggregated crisp ratings, $f_{j}^{*}$ and $f_{j}^{-}$of the 39 criteria.

Table 7 presents the $S_{i}, R_{i}$ and $Q_{i}$ values for the three alternatives computed using Eqs. (10-11).

The values of $S^{*}=0.324, S=0.675, R^{*}=0.029$, $R^{-}=0.0315$ are obtained using Eqs. (10-11).

Table 7 ranks the three alternatives, sorting by the values of $S_{i}, R_{i}$ and $Q_{i}$ obtained from Table 8 in ascending order.
It can be seen from the results of Table 8 that Site A2 is the best ranked by the measure $Q_{i}$ (minimum). We now check it for the following two conditions (Step 9):

(1) C1, acceptable advantage (Eq. (13)):

Using Eq. (14), $D Q=1 /(39-1)=1 / 38=0.0263$. Applying Eq. (13), we find $Q(A 1)-Q(A 2)=1-0=1>$ 0.0263 , hence the condition $Q A^{(1)}-Q A^{(2)} \geq D Q$ is

\begin{tabular}{|c|c|c|c|c|}
\hline Criteria & A1 (PWD) & A2 (DMRC) & Min & Max \\
\hline $\mathrm{C} 1$ & $(1,3.28,9)$ & $(1,5.12,9)$ & 1 & 9 \\
\hline $\mathrm{C} 2$ & $(1,4.08,9)$ & $(1,4.92,9)$ & 1 & 9 \\
\hline $\mathrm{C} 3$ & $(1,3.85,9)$ & $(1,4.52,9)$ & 1 & 9 \\
\hline $\mathrm{C} 4$ & $(1,4.72,9)$ & $(1,4.80,9)$ & 1 & 9 \\
\hline $\mathrm{C} 5$ & $(1,4.16,9)$ & $(1,5.12,9)$ & 1 & 9 \\
\hline C6 & $(1,3.40,9)$ & $(1,4.68,9)$ & 1 & 9 \\
\hline $\mathrm{C} 7$ & $(1,4.11,9)$ & $(1,4.28,9)$ & 1 & 9 \\
\hline $\mathrm{C} 8$ & $(1,3.86,9)$ & $(1,4.80,9)$ & 1 & 9 \\
\hline C9 & $(1,4.14,9)$ & $(1,4.32,9)$ & 1 & 9 \\
\hline $\mathrm{C} 10$ & $(1,4.86,9)$ & $(1,4.48,9)$ & 1 & 9 \\
\hline $\mathrm{C} 11$ & $(1,5.12,9)$ & $(1,4.67,9)$ & 1 & 9 \\
\hline $\mathrm{C} 12$ & $(1,4.56,9)$ & $(1,4.20,9)$ & 1 & 9 \\
\hline $\mathrm{C} 13$ & $(1,4.63,9)$ & $(1,4.92,9)$ & 1 & 9 \\
\hline $\mathrm{C} 14$ & $(1,5.72,9)$ & $(1,5.80,9)$ & 1 & 9 \\
\hline $\mathrm{C} 15$ & $(1,4.20,9)$ & $(1,5.08,9)$ & 1 & 9 \\
\hline $\mathrm{C} 16$ & $(1,4.80,9)$ & $(1,4.13,9)$ & 1 & 9 \\
\hline $\mathrm{C} 17$ & $(1,5.36,9)$ & $(1,4.68,9)$ & 1 & 9 \\
\hline $\mathrm{C} 18$ & $(1,2.44,7)$ & $(1,3.73,9)$ & 1 & 9 \\
\hline $\mathrm{C} 19$ & $(1,4.80,9)$ & $(1,4.44,9)$ & 1 & 9 \\
\hline $\mathrm{C} 20$ & $(1,4.32,9)$ & $(1,3.92,9)$ & 1 & 9 \\
\hline $\mathrm{C} 21$ & $(1,3.80,9)$ & $(1,4.80,9)$ & 1 & 9 \\
\hline $\mathrm{C} 22$ & $(1,4.68,9)$ & $(1,4.91,9)$ & 1 & 9 \\
\hline $\mathrm{C} 23$ & $(1,5.24,9)$ & $(1,4.72,9)$ & 1 & 9 \\
\hline $\mathrm{C} 24$ & $(1,4.96,9)$ & $(1,4.42,9)$ & 1 & 9 \\
\hline $\mathrm{C} 25$ & $(1,6.08,9)$ & $(1,5.45,9)$ & 1 & 9 \\
\hline $\mathrm{C} 26$ & $(1,3.40,9)$ & $(1,4.52,9)$ & 1 & 9 \\
\hline $\mathrm{C} 27$ & $(1,4.24,9)$ & $(1,4.36,9)$ & 1 & 9 \\
\hline $\mathrm{C} 28$ & $(1,3.81,7)$ & $(1,3.76,7)$ & 1 & 9 \\
\hline $\mathrm{C} 29$ & $(1,2.64,7)$ & $(1,4.68,9)$ & 1 & 9 \\
\hline $\mathrm{C} 30$ & $(1,3.24,9)$ & $(1,5.68,9)$ & 1 & 9 \\
\hline $\mathrm{C} 31$ & $(1,2.84,7)$ & $(1,5.08,9)$ & 1 & 9 \\
\hline C32 & $(1,2.48,7)$ & $(1,4.96,9)$ & 1 & 9 \\
\hline $\mathrm{C} 33$ & $(1,4.68,9)$ & $(1,5.56,9)$ & 1 & 9 \\
\hline C34 & $(1,4.24,9)$ & $(1,4.88,9)$ & 1 & 9 \\
\hline $\mathrm{C} 35$ & $(1,3.56,7)$ & $(1,4.56,9)$ & 1 & 9 \\
\hline $\mathrm{C} 36$ & $(1,2.60,7)$ & $(1,4.32,9)$ & 1 & 9 \\
\hline C37 & $(1,2.50,7)$ & $(1,2.33,7)$ & 1 & 7 \\
\hline C38 & $(1,2.16,5)$ & $(1,2.00,5)$ & 1 & 9 \\
\hline C39 & $(1,2.66,7)$ & $(1,2.85,7)$ & 1 & 9 \\
\hline
\end{tabular}
satisfied.

Table 5 Aggregate fuzzy decision matrix for the two alternative sites. 
Table 6 The best values $f_{j}^{*}$ and the worst values $f_{j}^{-}$of the 39 criteria.

\begin{tabular}{|c|c|c|c|c|}
\hline \multirow{2}{*}{ Criteria } & \multicolumn{2}{|c|}{ Crisp ratings } & \multirow{2}{*}{$f_{j}^{*}$} & \multirow{2}{*}{$f_{j}^{-}$} \\
\hline & A1 (PWD) & A2 (DMRC) & & \\
\hline C1 & 3.85 & 5.08 & 5.08 & 3.85 \\
\hline $\mathrm{C} 2$ & 4.39 & 4.95 & 4.95 & 4.39 \\
\hline $\mathrm{C} 3$ & 4.23 & 4.68 & 4.68 & 4.23 \\
\hline $\mathrm{C} 4$ & 4.81 & 4.87 & 4.87 & 4.81 \\
\hline $\mathrm{C} 5$ & 4.44 & 5.08 & 5.08 & 4.44 \\
\hline C6 & 3.93 & 4.79 & 4.79 & 3.93 \\
\hline $\mathrm{C} 7$ & 4.41 & 4.52 & 4.52 & 4.41 \\
\hline $\mathrm{C} 8$ & 4.24 & 4.87 & 4.87 & 4.24 \\
\hline C9 & 4.43 & 4.55 & 4.55 & 4.43 \\
\hline C10 & 4.91 & 4.65 & 4.91 & 4.65 \\
\hline $\mathrm{C} 11$ & 5.08 & 4.78 & 5.08 & 4.78 \\
\hline $\mathrm{C} 12$ & 4.71 & 4.47 & 4.71 & 4.47 \\
\hline $\mathrm{C} 13$ & 4.75 & 4.95 & 4.95 & 4.75 \\
\hline $\mathrm{C} 14$ & 5.48 & 5.53 & 5.53 & 5.48 \\
\hline $\mathrm{C} 15$ & 4.47 & 5.05 & 5.05 & 4.47 \\
\hline $\mathrm{C} 16$ & 4.87 & 4.42 & 4.87 & 4.42 \\
\hline $\mathrm{C} 17$ & 5.24 & 4.79 & 5.24 & 4.79 \\
\hline $\mathrm{C} 18$ & 2.96 & 4.15 & 4.15 & 2.96 \\
\hline C19 & 4.87 & 4.63 & 4.87 & 4.63 \\
\hline $\mathrm{C} 20$ & 4.55 & 4.28 & 4.55 & 4.28 \\
\hline $\mathrm{C} 21$ & 4.20 & 4.87 & 4.87 & 4.20 \\
\hline $\mathrm{C} 22$ & 4.79 & 4.94 & 4.94 & 4.79 \\
\hline $\mathrm{C} 23$ & 5.16 & 4.81 & 5.16 & 4.81 \\
\hline $\mathrm{C} 24$ & 4.97 & 4.61 & 4.97 & 4.61 \\
\hline $\mathrm{C} 25$ & 5.72 & 5.30 & 5.72 & 5.30 \\
\hline $\mathrm{C} 26$ & 3.93 & 4.68 & 4.68 & 3.93 \\
\hline C27 & 4.49 & 4.57 & 4.57 & 4.49 \\
\hline C28 & 3.87 & 3.84 & 3.87 & 3.84 \\
\hline C29 & 3.09 & 4.79 & 4.79 & 3.09 \\
\hline C30 & 3.83 & 5.45 & 5.45 & 3.83 \\
\hline C31 & 3.23 & 5.05 & 5.05 & 3.23 \\
\hline C32 & 2.99 & 4.97 & 4.97 & 2.99 \\
\hline C33 & 4.79 & 5.37 & 5.37 & 4.79 \\
\hline C34 & 4.49 & 4.92 & 4.92 & 4.49 \\
\hline C35 & 3.71 & 4.71 & 4.71 & 3.71 \\
\hline C36 & 3.07 & 4.55 & 4.55 & 3.07 \\
\hline C37 & 3.00 & 2.89 & 3.00 & 2.89 \\
\hline C38 & 2.44 & 2.33 & 2.44 & 2.33 \\
\hline C39 & 3.11 & 3.23 & 3.23 & 3.11 \\
\hline
\end{tabular}

Table $7 \quad S i, R i$ and $Q i$ values for the two alternative sites.

\begin{tabular}{lll}
\hline & A1 (PWD) & A2 (DMRC) \\
\hline$S_{i}$ & 0.674600575 & 0.323688903 \\
$R_{i}$ & 0.031553663 & 0.029843142 \\
$Q_{i}$ & 1 & 0 \\
\hline
\end{tabular}

Table 8 Alternative rankings.

\begin{tabular}{lll}
\hline$S_{i}$ & $\mathrm{~A} 2$ & $\mathrm{~A} 1$ \\
\hline$R_{i}$ & $\mathrm{~A} 2$ & $\mathrm{~A} 1$ \\
$Q_{i}$ & $\mathrm{~A} 2$ & $\mathrm{~A} 1$ \\
\hline
\end{tabular}

(2) C2, acceptable stability in decision making:

Since Site $\mathrm{A} 2$ is also best ranked by $S_{i}$ and $R_{i}$ (considering by consensus rule, $v=0.5$ ), it is ranked as a more sustainable corridor.

Otherwise also, if we look at the site management of two corridors, it is seen that DMRC corridor is better managed with proper barricading system and systematic diversion of traffic. The signages put on the corridor for guiding the traffic while moving through the corridor are well defined and duly controlled with marshals in proper uniform and required gadgets like flags and whistle items. The project details with targets are displayed properly. The site has been kept neat and clean. Safety measures for the workers are found to be better at DMRC site. It gives an impression that the management is sensitive towards SHE (safety, health and environmental) issues or in other words the governance at DMRC site was much better than PWD corridor. Even from the point of view of technological aspects, especially for larger spans designed for crossing over a water body with CLC (canti-lever construction) by DMRC is technically sound and aesthetically pleasing than the similar situation at PWD corridor where the water body is crossed over by providing intermediate portals to reduce the span.

\section{Conclusions}

During the research study conducted at two project sites in thickly urban environment and the peak of the construction period, it was observed that there is a need to be sensitive towards all stakeholders. When we use the term stakeholders, it is not limited to the project team comprising of mangers, contractors, consultants or the workmen. Everyone bearing the burden of construction, all residents living nearby and the commuters passing through the project corridor are equal participants in the construction activities. Even 
the environment all around cannot be ignored. The trees, the shrubs and flowers play a vital role for which the construction should be sensitive for its maintenance. In addition to this, the utilities, like drainage system, telephone lines, electrical cables, gas lines etc., are required to be properly maintained.

For a developing country, like India, and its capital city Delhi, the construction activities will be called sustainable only if the project planning includes all such activities and includes the cost of its caring in the project cost. The concept of three pillars is limited to only developed nations, where the people are sensitive towards society, environment and economics. But for a developing city, the other parameters or indicators, as identified like governance, technological deployment, as well as inner engineering, play a vital role [21].

After making a study at two corridors and applying the fuzzy VIKOR technique in analysis, it was found that DMRC is more sustainable than PWD as far as the construction in urban environment is concerned.

\section{Future Work}

In this paper, we have limited the studies to identify the sustainability indicators and demonstrate the application of fuzzy VIKOR technique for sustainability evaluation of the urban transportation corridor. In our future works, we intend to develop a green rating system for transportation corridors in an urban environment. This paper will serve as a reference for the implementation of the most suitable sustainability indicators during construction of a transportation infrastructure. A green rating system will encourage the development of technologies based on the criteria used for evaluating transportation infrastructures/corridors, as well as developing sustainable technologies.

\section{References}

[1] WCED (World Commission on Environment and Development). 1987. Our Common Future. Oxford: Oxford University Press.

[2] Jeon, C. M., and Amekudzi, A. 2005. "Addressing
Sustainability in Transportation Systems: Definitions, Indicators, and Metrics." Journal of Infrastructure Systems, ASCE (American Society of Civil Engineers) 11 (1): 31-50.

[3] Litman, T. 2003. Sustainable Transportation Indicators. A Recommended Research Program for Developing Sustainable Transportation Indicators and Data by the Sustainable Transportation Indicators Subcommittee of the Transportation Research Board. Victoria: VTPI (Victoria Transport Policy Institute).

[4] Litman, T. 2009. "Sustainable Transportation Indicators-A Recommended Research Program for Developing Sustainable Transportation Indicators and Data." Presented at the 2009 Transportation Research Board Annual Conference, Washington, D.C., USA.

[5] Van Wee, B., and Geurs, K. 2000. "Backcasting as a Tool to Develop a Sustainable Transport Scenario Assuming Emission Reductions of 80 90\%." Innovation 13 (1): 47-62.

[6] Litman, T. 2008. Well Measured: Developing Indicators for Comprehensive and Sustainable Transport Planning. Columbia: Victoria Transport Policy Institute.

[7] Zuidgeest, M. H. P. 2005. "Sustainable Urban Transport Development-A Dynamic Optimization Approach." $\mathrm{Ph} . \mathrm{D}$. thesis, University of Twente.

[8] Opricovic, S. 1998. Multi-criteria Optimization of Civil Engineering Systems. Belgrade: Faculty of Civil Engineering.

[9] Wu, M., and Liu, Z. J. 2011. "The Supplier Selection Application Based on Two Methods: VIKOR Algorithm with Entropy Method and Fuzzy TOPSIS with Vague Sets Method." International Journal of Management Science and Engineering Management 6 (2): 936-46.

[10] Awasthi, A., Omrani, H., and Gerber, P. 2013. Multi-criteria Decision Making for Sustainability Evaluation of Urban Mobility Projects. Working Paper No. 2013-01. CEPS Instead,

[11] Opricovic, S., and Tzeng, G. H. 2007. "Extended VIKOR Method in Comparison with Outranking Methods." European Journal of Operational Research 178 (2): 514-29.

[12] Buckley, J. J. 1985. "Fuzzy Hierarchy Analysis." Fuzzy Sets and Systems 17: 233-47.

[13] Dubois D., and Prade H. 1987. Possibility Theory: An Approach to Computerized Processing of Uncertainty. New York: Plenum Ed.

[14] Kaufmann, A., and Gupta, M. M. 1991. Introduction to Fuzzy Arithmetic: Theory and Application. New York: Van Nostrand Reinhold.

[15] Klir, G. J., and Yuan, B. 1995. Fuzzy Sets and Fuzzy Logic. Theory and Applications. Upper Saddle River: Prentice-Hall PTR. 
[16] Pedrycz, W. 1994. "Why Triangular Membership Functions?." Fuzzy Sets and Systems 64 (1): 21-30.

[17] Zadeh, L. 1965. "Fuzzy Sets." Information and Control 8 (3): 338-53.

[18] Zimmermann, H. J. 2001. Fuzzy Set Theory and Its Applications. 4th ed. Boston: Kluwer Academic Publishers.

[19] Samantra, C., Datta, S., and Mahapatra, S. S. 2012. "Application of Fuzzy Based VIKOR Approach for Multi-attribute Group Decision Making (MAGDM): A
Case Study in Supplier Selection." Decision Making in Manufacturing and Services 6 (1): 25-39.

[20] Wang, T. C., and Chang, T. H. 2005. "Fuzzy VIKOR as an Aid for Multiple Criteria Decision Making.” Presented at 10th Annual Meeting of Asia Pacific Conference, Taiwan.

[21] Shishir, B., Sameer, V., and Singh, S. K. 2014. "Sustainability Indicators of a Transportation Corridor during Construction in an Urban Environment." Presented at International Conference on Sustainable Civil Infrastructure 2014, Hyderabad, India. 